Article

\title{
Performance of the Adult ADHD Self-Report Scale-v1.1 in Adults with Major Depressive Disorder
}

\author{
Boadie W. Dunlop ${ }^{1, *(\mathbb{D})}$, Ruizhe $\mathrm{Wu}^{2}{ }^{(\mathbb{D})}$ and Kathleen Helms ${ }^{1}$ \\ 1 Department of Psychiatry and Behavioral Sciences, School of Medicine, Emory University, 12 Executive Park \\ Drive, 3rd Floor, Atlanta, GA 30329, USA; kat.helms3@gmail.com \\ 2 School of Public Health, Emory University, Atlanta, GA 30329, USA; ruizhe.wu@emory.edu \\ * Correspondence: bdunlop@emory.edu; Tel.: +1-404-727-8474; Fax: +1-404-727-3700
}

Received: 26 January 2018; Accepted: 27 March 2018; Published: 29 March 2018

\begin{abstract}
Attention deficit/hyperactivity disorder (ADHD) is an under-recognized comorbid disorder among patients with mood disorders. ADHD is an independent risk factor for suicidal ideation and behavior and contributes to many aspects of impaired function in adults. Diagnosis of ADHD in Major Depressive Disorder (MDD) patients is challenging due to the overlap in cognitive symptoms between the two disorders. The ADHD Self-Report Scale, version 1.1 (ASRS-v1.1) is a widely used screening instrument for ADHD in adults but its accuracy has not been evaluated previously in treatment-seeking MDD patients. We administered the ASRS-v1.1 to 55 healthy controls and 40 adults with a primary psychiatric diagnosis of MDD who were participating in clinical research studies. ADHD diagnosis was assessed via structured interview with the adult ADHD module of the Mini International Neuropsychiatric Interview Plus version 6.0.0 (MINI) along with a psychiatrist's assessment. Overall, full-syndrome ADHD was diagnosed in $12.5 \%$ of the MDD patients. MDD patients endorsed all 18 items of the ASRS-v1.1 more frequently than the healthy controls and the number of ASRS-v1.1 items endorsed correlated with levels of anxiety in the MDD patients. The ASRS-v1.1 demonstrated fair performance for identifying full syndrome DSM-IV ADHD diagnosis, with sensitivity $60 \%$, specificity: $68.6 \%$, positive predictive value $21.4 \%$, negative predictive value $92.3 \%$ and total classification accuracy of $67.5 \%$. Positive predictive value improved substantially when the ADHD criterion requiring symptom onset before age 7 was omitted. In adult MDD patients, a negative ASRS-v1.1 screen strongly suggests the absence of ADHD but positive screen results require careful evaluation to determine whether self-reported ADHD symptoms simply emerge from depression or whether comorbid ADHD is present.
\end{abstract}

Keywords: screening; comorbidity; depression; attention; cognitive impairment; anxiety

\section{Introduction}

Attention deficit/hyperactivity disorder (ADHD) is a neurodevelopmental disorder characterized by hyperactivity, inattentiveness and impulsivity that onsets during childhood [1]. Although symptoms may diminish in adulthood, the full syndrome commonly persists [2], afflicting an estimated 1.2-7.3\% of adults around the world [3], including $4.4 \%$ of adults in the United States [4]. Individuals with ADHD experience substantially greater financial burdens, more accidents, incur more health care costs and engage in more criminal behaviors than people without a history of ADHD [5,6]. ADHD can be classified as a primarily inattentive type, primarily hyperactive-impulsive type, or a combined type when criteria for both types are met. Inattentive symptoms, such as daydreaming and forgetfulness, are particularly detrimental to maintaining satisfactory work productivity [7].

Adults with ADHD have substantially ( $2-3$ fold) higher rates of having mood, anxiety, or substance use disorders, as established by both epidemiological $[3,8]$ and clinical studies $[9,10]$. 
However, the reciprocal relationships (i.e., the proportion of adults with specific psychiatric disorders who also have ADHD) has been less frequently examined. In the National Comorbidity Survey Revised, a community household survey, the prevalence of ADHD among adults with Major Depressive Disorder (MDD) was 9.4\%. Similar rates of ADHD were found among adults with any anxiety disorder $(9.5 \%)$ or any substance use disorder $(10.4 \%)$, all of which were roughly half the rate of $21 \%$ among adults with bipolar disorder [8].

The limited data about ADHD among patients with depressive disorders represents a particularly important knowledge gap. The clinical significance of identifying ADHD comorbidity among patients with depression is evident in the greater levels of functional impairment, longer depressive episodes and the increased suicidal ideation and behavior among comorbid patients than those with MDD without ADHD [11,12]. Despite the demonstrated importance of ADHD comorbidity, only two published studies have examined the prevalence of ADHD in a psychiatric setting among adults with MDD in a major depressive episode, finding a 7.6\% [13] to 14\% [9] prevalence. The symptoms of ADHD, particularly those related to inattention, are frequently experienced by patients with mood, anxiety, or substance use disorders, even among patients without comorbid ADHD, which complicates diagnostic efforts. Due to the symptomatic overlap of ADHD with other disorders, particularly cognitive symptoms but also irritability, anxiety, psychomotor agitation and sleep problems [14], many clinicians struggle to detect, diagnose and treat ADHD when present $[15,16]$. Conversely, limitations in time or expertise may hinder clinicians' efforts to rule out a diagnosis of ADHD when symptoms of inattention, hyperactivity, or impulsivity are better explained by another psychiatric condition.

A widely used screening instrument for identifying adult ADHD is the Adult ADHD Self-Report Scale, version 1.1 (ASRS-v1.1). Using a total score of $\geq 4$ on the six-item Part A section of the scale as the threshold to indicate a positive screening test, the developers of the ASRS-v1.1 reported moderate sensitivity $(68.7 \%)$, along with excellent specificity $(99.5 \%)$ and total classification accuracy $(97.9 \%)$ when assessing symptoms among a community sample [17]. Despite performing well as a screening instrument in general adult populations, the ASRS-v1.1's accuracy in comorbid populations is more inconsistent $[18,19]$. Although it is crucial to accurately identify ADHD when it is present in patients with MDD, there are important iatrogenic risks that arise from over-diagnosis, such as inappropriate prescribing of stimulant medications, which may induce addiction and adversely impact cardiovascular health [20]. Consequently, there is great clinical relevance for fully understanding the utility of ADHD screening in patients with primary psychiatric disorders such as MDD.

Remarkably, there are no published studies on the accuracy of the ASRS-v1.1 among adults with MDD. Here we report an evaluation of the ASRS-v1.1 among a sample of adult outpatients with MDD participating in clinical research studies. We hypothesized that the ASRS-v1.1 would have high sensitivity and negative predictive value but low positive predictive value, due to the expectation that depressed patients would frequently endorse the inattentive and procrastination items on part A of the instrument.

\section{Materials and Methods}

The data being analyzed for this paper was collected from two studies of MDD that enrolled adult healthy control subjects and MDD patients through the Mood and Anxiety Disorders Program at Emory University in Atlanta, Georgia, between August 2013 and September 2016. Both studies compared healthy control (HC) adults with those with MDD. One study examined a blood test for MDD (data not published); the other examined differences in decision-making between adults with and without MDD (clinicaltrials.gov NCT01916824) [21]. The institutional review board of the Emory University approved both studies. Written informed consent was obtained from all participants and all data were de-identified. 


\subsection{Participants}

The psychiatric assessment procedure for both studies was identical (described below) and both studies enrolled adult men and women, ages 18-65 using similar inclusion and exclusion criteria. Eligibility criteria for HC included absence in the past year of a DSM-IV mental illness diagnosis (including ADHD), no history of MDD or dysthymia, no history of psychotropic medication use and a score of $\leq 7$ on the 17-item Hamilton Depression Rating Scale (HDRS) [22]. Depressed patients had to meet a primary DSM-IV psychiatric diagnosis of non-psychotic MDD, score $\geq 15$ on the HDRS and be off all psychiatric medications (other than sedative/hypnotic) for one month prior to assessment. For all participants, exclusion criteria included meeting DSM-IV criteria for a lifetime diagnosis of bipolar disorder, a primary psychotic disorder (e.g., schizophrenia), or dementia, the presence of any unstable or central nervous system or other medical illness that would interfere with cognition or participation, or presenting with a level of suicide risk, as evaluated by a study physician, that required urgent intervention.

\subsection{Measures}

All participants were assessed with the Structured Interview for DSM-IV (SCID) [23] and the Mini International Neuropsychiatric Interview Plus version 6.0.0 (MINI) Adult ADHD Module (module TA) [24]. This module of the MINI is divided into three sections: TA1, comprised of the 9 DSM-IV ADHD inattention criteria; TA2, comprised of the 9 DSM-IV ADHD hyperactivity/impulsivity criteria; TA3, a question whether the symptoms from TA1 or TA2 began before the age of 7; and TA4, a question whether the symptoms caused functional problems at work, school, home, or with family or friends. For the current analysis, if six or more items from section TA1 or section TA2 were endorsed, symptom count criteria for ADHD were considered met. To achieve the formal diagnosis of DSM-IV adult ADHD, participants also had to be scored positively on both sections TA3 and TA4 and have the diagnosis confirmed by a study psychiatrist. To confirm the diagnoses of ADHD, the study psychiatrist assessed the temporal course of ADHD symptoms and established that the symptoms of ADHD had emerged prior to the first lifetime depressive episode and could not be better explained by another psychiatric diagnosis (DSM-IV Criterion E), including posttraumatic stress disorder arising from traumatic events experienced in childhood. The SCID was used to confirm the diagnosis of MDD among depressed participants and to identify comorbid psychiatric disorders.

The ASRS-v1.1 is a self-report form used to assess symptoms of ADHD based on the 18 DSM-IV symptom criteria [17]. The instrument is comprised of two parts: Part A (6 questions) and Part B (12 questions). For each item, respondents are asked to indicate how often the stated symptom occurred over the prior six months, with five options: never, rarely, sometimes, often, or very often. For all 18 items, responses of "often" or "very often" are considered positive (indicated by shaded boxes on the questionnaire). In addition, for items 1, 2, 3, 9, 12, 16 and 18, a response of "sometimes" is also scored positive. A patient is considered to screen positive on the ASRS-v1.1 if they endorse 4 or more of the Part A questions at these threshold levels. Although Part B is not used for diagnostic purposes, these items provide insight into the frequency of symptoms and can be used to help elicit other the symptoms the patient may suffer from [15].

To assess depression severity, the HDRS was administered and a study physician scored the Clinical Global Impression-Severity (CGI-S) [25]. The Hamilton Anxiety Rating Scale (HAMA) [26] was used to assess severity of anxiety symptoms. To examine the level of rumination over negative cognitions, the self-report Ruminative Responses Scale (RRS) [27] was completed. The RRS is a self-report questionnaire that assesses the frequency of rumination using a 1 (almost never) to 4 (almost always) scale for 22 items. Higher scores on all three of these scales reflect greater severity of the symptoms. The Childhood Trauma Questionnaire (CTQ) [28], a 28-item self-report instrument, was used as a measure of adverse childhood experiences. The CTQ asks about five kinds of childhood maltreatment, scoring each item from 0 to 5 (never true to very often true). Self-report assessments were administered after the clinician-rated measures. 


\subsection{Statistical Analysis}

Consistent with the standard screening threshold for the ASRS-v1.1, participants who scored $\geq 4$ on Part A of the questionnaire were considered to screen positive for ADHD. The gold standard for formal ADHD diagnosis was meeting all DSM-IV diagnostic criteria for ADHD as assessed by module TA of the MINI, along with confirmation of the diagnosis by a study psychiatrist's interview. There has been growing concern that the DSM-IV requirement that ADHD symptoms be present before the age of 7 excludes many afflicted individuals [29], which led to the diagnostic revision in DSM-5 that symptoms should be present before the age of 12 [1]. Consequently, to more broadly examine ADHD symptoms among participants who may have been excluded due to the DSM-IV age 7 criterion, we also classified any participant who endorsed six or more items on section TA1 or TA2 of the MINI as meeting the symptom count criterion for ADHD.

Mean scores on the study measures were calculated and compared using independent sample $t$-tests to compare those meeting the case definitions of ADHD and separately for those meeting the ASRS-v1.1 positive screening threshold. To control for multiple comparisons across the ASRS-v1.1 items, we applied a Bonferroni correction, requiring a $p$-value of $0.00278(0.05 / 18)$ to indicate statistical significance. We also evaluated categorical associations with these measures using Chi Square tests, applying Fisher's exact test when cell sizes had expected values $<5$.

To assess the operating characteristics of the ASRS-v1.1 in our sample, two-way tables were constructed to calculate the sensitivity, specificity, positive predictive value (PPV) and negative predictive value (NPV) and accuracy of the ASRS-v1.1. These measures were calculated separately for two different case definitions: (1) those who met the symptom count criteria definition on the MINI and (2) those who met the full formal DSM-IV diagnostic criteria.

\section{Results}

\subsection{Participants}

There were 40 MDD and 55 HC participants across the two studies with complete MINI and ASRS-v1.1 data. Demographic characteristics were similar across the two groups. The HC sample had a mean age of $44.0 \pm 11.5$ years, was $70.9 \%$ female and had a race distribution of $50.9 \%$ African-American, $29.1 \%$ white and $20 \%$ multiple or another race. The MDD sample had a mean age of $49.5 \pm 8.1$, was $72.5 \%$ female, with a race distribution of $32.5 \%$ African-American, $47.5 \%$ white and $20 \%$ multiple or another race.

\subsection{ASRS-v1.1 Descriptive Results}

Figure 1 shows a clustered histogram of the ASRS-v1.1 items between the MDD and HC participants. MDD participants scored significantly higher on all 18 items (all $p<0.00278$ ). Because the ASRS-v1.1 is a screening tool to identify people who endorse the items at a frequency that suggests an ADHD diagnosis, we also examined the proportion of subjects endorsing each item at a level qualifying as a significant symptom (i.e., in the shaded box on the questionnaire).

As shown in Table 1, MDD participants endorsed many of the ASRS-v1.1 items at a high frequency. In particular, the items regarding difficulties with wrapping up details of projects, listening when being spoken to directly, or getting organized for a project were all endorsed at the threshold level by $\geq 60 \%$ of the MDD participants. Indeed, four of the six Part A items that are used as the screen for ADHD were endorsed at the threshold level by $\geq 45 \%$ of the MDD participants. In contrast, the last item in Part A (number 6, feeling driven by a motor) was the item endorsed leased frequently by MDD participants, at $10 \%$. The 55 HC participants rarely endorsed items at the threshold level; the most frequently endorsed item was number 16 (finishing the sentences of other people) at $5.5 \%$. 


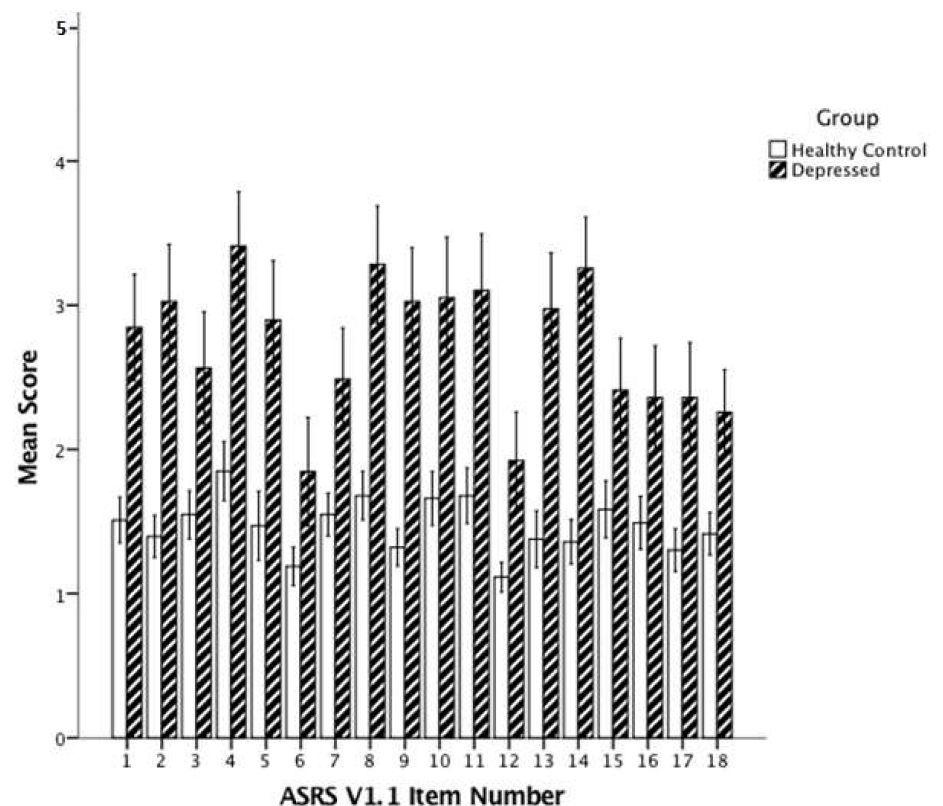

Figure 1. Mean scores for the 18 ASRS-v1.1 items in healthy control and depressed patients. ASRS-v1.1: Adult ADHD Self-Report Scale Symptom Checklist. Note: To quantify responses, we assigned a numerical score to each of the five response options: "never" = 1 ; "rarely" = 2; "sometimes" = 3; "often" $=4$; "very often" $=5$. All $p<0.005$. Error bars: 95\% CI.

Table 1. Proportion of the 40 Major Depressive Disorder (MDD) participants endorsing each ASRS-v1.1 item at a frequency that suggests the symptom is consistent with a diagnosis of Attention Deficit/ Hyperactivity Disorder (ADHD).

\begin{tabular}{clcc}
\hline Item No. & \multicolumn{1}{c}{ Item Description } & Number Endorsing & $\%$ \\
\hline 1 & Trouble wrapping up final details of a project & 25 & 62.5 \\
\hline 9 & $\begin{array}{l}\text { Difficulty concentrating on what people say to you, even when speaking } \\
\text { to you directly. }\end{array}$ & 25 & 62.5 \\
\hline 2 & Difficulty getting things in order for a task requiring organization & 24 & 60.0 \\
\hline 4 & Avoiding getting started on a task requiring a lot of thought & 19 & 47.5 \\
\hline 3 & Problems remembering appointments or obligations & 18 & 45.0 \\
\hline 8 & Difficulty keeping your attention when doing boring or repetitive work & 17 & 42.5 \\
\hline 16 & $\begin{array}{l}\text { Finishing sentences of people you are talking to before they can finish } \\
\text { them themselves }\end{array}$ & 17 & 42.5 \\
\hline 10 & Misplacing or having difficulty finding things at home or work & 15 & 37.5 \\
\hline 14 & Difficulty unwinding and relaxing when you have time to yourself & 15 & 37.5 \\
\hline 5 & $\begin{array}{l}\text { Fidget or squirm with your hands or feet when you have to sit down for } \\
\text { a long time }\end{array}$ & 13 & 32.5 \\
\hline 18 & Interrupting others when they are busy & 13 & 32.5 \\
\hline 11 & Distracted by activity or noise around you & 12 & 30.0 \\
\hline 13 & Feel restless or fidgety & 12 & 30.0 \\
\hline 12 & $\begin{array}{l}\text { Leave your seat in meetings or situations in which you are expected to } \\
\text { remain still }\end{array}$ & 8 & 20.0 \\
\hline 7 & $\begin{array}{l}\text { Make careless mistakes when you have to work on a boring or } \\
\text { difficulty project }\end{array}$ & 7 & 17.5 \\
\hline 15 & Find yourself talking too much when you are in social situations & 7 & 17.5 \\
\hline 17 & Difficulty waiting your turn in situations when turn taking is required & 6 & 15.0 \\
\hline 6 & $\begin{array}{l}\text { Feel overly active and compelled to do things, like you were driven by } \\
\text { a motor }\end{array}$ & 4 & 10.0 \\
\hline
\end{tabular}




\subsection{ADHD Symptoms and Diagnosis by MINI}

Based on the MINI ADHD module assessment, 20 participants (15 women and 5 men) met symptom count criteria for adult ADHD (16 inattentive type; 4 combined type). These 20 participants were all from the MDD patient group, indicating that $50 \%$ of MDD patients endorsed a sufficient number of current inattention symptoms to meet the symptom count criterion for ADHD. Of the 20 meeting the symptom count criterion, only 7 continued to meet full diagnostic criteria after application of criterion TA3 (onset of symptoms before age 7) and 2 of these did not meet the TA4 criterion of functional impairment, resulting in only 5 of the 40 MDD participants (12.5\%) meeting the full DSM-IV diagnostic criteria for ADHD (2 inattentive and 3 combined type). The psychiatrists' assessments did not change any of these participants' ADHD diagnoses. We also examined the effect of applying the DSM-5 ADHD diagnosis threshold of $\geq 5$ symptoms of a subtype (as opposed to $\geq 6$ required for DSM-IV). Six additional MDD patients would have met the DSM-5 reduced symptom count criterion (2 inattentive subtype, 4 hyperactivity/impulsivity subtype), totaling 26/40 (65\%) of the MDD sample.

Table 2 compares the 20 ADHD symptom-count criterion positive MDD participants versus the 20 MDD participants who did not meet the symptom count criterion. Notably, depression severity did not differ between the two groups of depressed patients. However, the patients who met ADHD symptom count criterion reported higher levels of anxiety as assessed by the HAMA.

Table 2. Comparison of MDD patients who do or do not meet the DSM-IV inattentive symptom count criterion for ADHD on the MINI.

\begin{tabular}{|c|c|c|c|c|c|c|}
\hline \multirow[b]{2}{*}{ Characteristic } & \multicolumn{2}{|c|}{$\begin{array}{l}\text { MINI ADHD Inattentive } \\
\text { Symptom Count Criterion } \\
\text { Negative }(n=20)\end{array}$} & \multicolumn{2}{|c|}{$\begin{array}{l}\text { MINI ADHD Inattentive } \\
\text { Symptom Count Criterion } \\
\text { Positive }(n=20)\end{array}$} & \multirow[b]{2}{*}{$t$} & \multirow[b]{2}{*}{$p$} \\
\hline & Mean & SD & Mean & SD & & \\
\hline Age (years) & 49.4 & 8.4 & 49.7 & 7.9 & 0.14 & 0.89 \\
\hline Age at first episode (years) & 27.1 & 15.5 & 33.3 & 16.0 & 1.19 & 0.24 \\
\hline Number of episodes & 2.3 & 1.2 & 2.3 & 1.3 & 0.13 & 0.90 \\
\hline HDRS & 20.1 & 3.2 & 21.3 & 3.9 & 1.03 & 0.31 \\
\hline CGI-S & 4.2 & 0.6 & 4.3 & 0.6 & 0.53 & 0.60 \\
\hline HAMA & 18.1 & 4.2 & 19.6 & 4.9 & 1.02 & 0.32 \\
\hline HAMA Item 5 (Concentration) & 1.9 & 0.8 & 2.5 & 0.5 & 3.03 & 0.004 \\
\hline CTQ Total & 66.9 & 17.7 & 67.2 & 12.2 & 0.05 & 0.96 \\
\hline RRS & 56.0 & 10.0 & 60.1 & 10.3 & 1.13 & 0.227 \\
\hline ASRS-v1.1 Part A & 1.9 & 1.5 & 3.3 & 1.8 & 2.79 & 0.008 \\
\hline ASRS-v1.1 Part B & 2.2 & 2.2 & 5.6 & 3.7 & 3.54 & 0.001 \\
\hline \multirow[t]{2}{*}{ ASRS-v1.1 Total } & 4.0 & 3.2 & 8.9 & 5.3 & 3.50 & 0.001 \\
\hline & $\mathbf{N}$ & $\%$ & $\mathbf{N}$ & $\%$ & $x^{2}$ & $p$ \\
\hline Sex & & & & & 0.13 & 0.72 \\
\hline Male & 6 & 30 & 5 & 25 & & \\
\hline Female & 14 & 70 & 15 & 75 & & \\
\hline Race * & & & & & 4.58 & 0.10 \\
\hline White & 12 & 67 & 7 & 35 & & \\
\hline Black & 5 & 28 & 8 & 40 & & \\
\hline Other/Multiple & 1 & 6 & 5 & 25 & & \\
\hline Marital Status * & & & & & 0.21 & 0.65 \\
\hline Married/Partnered & 7 & 35 & 8 & 42 & & \\
\hline Single & 13 & 65 & 11 & 58 & & \\
\hline Currently Employed & & & & & 0.44 & 0.51 \\
\hline Yes & 12 & 60 & 14 & 70 & & \\
\hline No & 8 & 40 & 6 & 30 & & \\
\hline Lifetime Anxiety Disorder & & & & & 0.40 & 0.53 \\
\hline
\end{tabular}


Table 2. Cont

\begin{tabular}{|c|c|c|c|c|c|c|}
\hline \multirow[b]{2}{*}{ Characteristic } & \multicolumn{2}{|c|}{$\begin{array}{l}\text { MINI ADHD Inattentive } \\
\text { Symptom Count Criterion } \\
\text { Negative }(n=20)\end{array}$} & \multicolumn{2}{|c|}{$\begin{array}{l}\text { MINI ADHD Inattentive } \\
\text { Symptom Count Criterion } \\
\text { Positive }(n=20)\end{array}$} & \multirow[b]{2}{*}{$t$} & \multirow[b]{2}{*}{$p$} \\
\hline & Mean & SD & Mean & SD & & \\
\hline Yes & 10 & 50 & 8 & 42 & & \\
\hline No & 10 & 50 & 12 & 58 & & \\
\hline Lifetime Tobacco Use & & & & & 1.0 & 1.0 \\
\hline Yes & 10 & 50 & 10 & 50 & & \\
\hline No & 10 & 50 & 10 & 50 & & \\
\hline Lifetime Substance Abuse & & & & & 1.76 & 0.19 \\
\hline Yes & 5 & 25 & 9 & 45 & & \\
\hline No & 15 & 75 & 11 & 55 & & \\
\hline History of Stimulant Rx & & & & & 0.23 & 0.63 \\
\hline Yes & 3 & 15 & 2 & 10 & & \\
\hline No & 17 & 85 & 2 & 90 & & \\
\hline
\end{tabular}

For the 5 formal DSM-IV diagnosis ADHD patients, no significant differences emerged between them and the 35 other MDD patients on any of the categorical or continuous variables.

\subsection{Utility of ASRS-v1.1 in Depressed Patients}

Fourteen of the 40 MDD patients screened positive on the ASRS-v1.1 Part A, with a score $\geq 4$. As shown in Table 3, the screen positive patients had significantly higher anxiety (HAMA) scores. They also scored significantly higher on HAMA item 5 (Concentration impairment) and on the RRS. Among all 40 MDD patients, the number of ASRS-v1.1 items endorsed at the threshold level was positively correlated with anxiety (HAMA score), both for Part A $(r=0.336, p=0.036)$ and for all 18 ASRS-v1.1 items $(r=0.394, p=0.013)$ (Figure 2a). The correlation with anxiety was stronger for ASRS-v1.1 screen negative MDD patients (Figure 2b) than for screen positive patients (Figure 2c), though the association was not significant for either group.

Table 3. Comparison of MDD patients who screened positive versus negative for ADHD on the ASRS-v1.1.

\begin{tabular}{|c|c|c|c|c|c|c|}
\hline \multirow[b]{2}{*}{ Characteristic } & \multicolumn{2}{|c|}{$\begin{array}{c}\text { ASRS-v1.1 Part A } \\
\text { Screen Negative }(n=26)\end{array}$} & \multicolumn{2}{|c|}{$\begin{array}{c}\text { ASRS-v1.1 Part A } \\
\text { Screen Positive }(n=14)\end{array}$} & \multirow[b]{2}{*}{$t$} & \multirow[b]{2}{*}{$p$} \\
\hline & Mean & SD & Mean & SD & & \\
\hline Age (years) & 48.2 & 8.2 & 52.1 & 7.6 & 1.49 & 0.15 \\
\hline Age at first episode (years) & 30.1 & 14.7 & 30.2 & 18.3 & 0.02 & 0.99 \\
\hline Number of episodes & 2.3 & 1.2 & 2.4 & 1.4 & 0.26 & 0.80 \\
\hline HDRS & 20.1 & 3.1 & 21.8 & 4.1 & 1.48 & 0.15 \\
\hline CGI-S & 4.2 & 0.6 & 4.4 & 0.5 & 1.43 & 0.16 \\
\hline HAMA & 17.8 & 4.3 & 20.9 & 4.5 & 2.14 & 0.039 \\
\hline HAMA Item 5 (Concentration) & 2.0 & 0.7 & 2.5 & 0.5 & 2.57 & 0.014 \\
\hline CTQ Total & 64.5 & 12.6 & 71.8 & 18.0 & 1.43 & 0.16 \\
\hline RRS & 55.6 & 9.4 & 62.8 & 10.6 & 2.10 & 0.042 \\
\hline No. MINI Inattention items & 4.1 & 2.3 & 6.8 & 2.5 & 3.42 & 0.002 \\
\hline \multirow[t]{2}{*}{ No. MINI Hyperactivity items } & 1.9 & 1.7 & 3.7 & 2.3 & 2.86 & 0.007 \\
\hline & $\mathbf{N}$ & $\%$ & $\mathbf{N}$ & $\%$ & $x^{2}$ & $p$ \\
\hline Sex & & & & & 0.40 & 0.52 \\
\hline Male & 8 & 31 & 3 & 21 & & \\
\hline Female & 18 & 69 & 11 & 79 & & \\
\hline
\end{tabular}


Table 3. Cont.

\begin{tabular}{|c|c|c|c|c|c|c|}
\hline \multirow[b]{2}{*}{ Characteristic } & \multicolumn{2}{|c|}{$\begin{array}{c}\text { ASRS-v1.1 Part A } \\
\text { Screen Negative }(n=26)\end{array}$} & \multicolumn{2}{|c|}{$\begin{array}{c}\text { ASRS-v1.1 Part A } \\
\text { Screen Positive }(n=14)\end{array}$} & \multirow[b]{2}{*}{$t$} & \multirow[b]{2}{*}{$p$} \\
\hline & Mean & SD & Mean & SD & & \\
\hline Race* & & & & & 0.13 & 0.94 \\
\hline White & 12 & 46 & 7 & 50 & & \\
\hline Black & 9 & 35 & 4 & 29 & & \\
\hline Other/Multiple & 4 & 15 & 2 & 14 & & \\
\hline Marital Status * & & & & & 0.05 & 0.49 \\
\hline Married/Partnered & 9 & 35 & 6 & 46 & & \\
\hline Single/Widowed/Divorced & 17 & 65 & 7 & 54 & & \\
\hline Currently Employed & & & & & 0.39 & 0.53 \\
\hline Yes & 16 & 62 & 10 & 71 & & \\
\hline No & 10 & 38 & 4 & 29 & & \\
\hline Lifetime Anxiety Disorder & & & & & 0.04 & 0.84 \\
\hline Yes & 12 & 46 & 6 & 43 & & \\
\hline No & 14 & 54 & 8 & 57 & & \\
\hline Lifetime Tobacco Use & & & & & 0.44 & 0.51 \\
\hline Yes & 12 & 46 & 8 & 57 & & \\
\hline No & 14 & 54 & 6 & 43 & & \\
\hline Lifetime Substance Abuse & & & & & 0.58 & 0.45 \\
\hline Yes & 8 & 31 & 6 & 43 & & \\
\hline No & 18 & 69 & 8 & 57 & & \\
\hline History of Stimulant Rx & & & & & 5.09 & 0.043 \\
\hline Yes & 1 & 4 & 4 & 29 & & \\
\hline No & 25 & 96 & 10 & 71 & & \\
\hline
\end{tabular}

Using the standard cut-off of $\geq 4$ ASRS-v1.1 Part A items to indicate a positive ADHD screen, we found fair performance of the ASRS v1.1 as a screener in the MDD sample. Defining the 20 symptom-criteria level ADHD subjects as "cases" (i.e., ignoring the requirement for onset of symptoms before age 7 and functional impairment), the ASRS-v1.1 had a sensitivity of $55.0 \%$ (95\% CI: 31.5-76.9\%), specificity $85.0 \%$ (95\% CI: 62.1-96.8\%), PPV 78.6\% (95\% CI: 54.6-91.8\%), NPV 65.4\% (95\% CI: $52.9-76.0 \%$ ) and total classification accuracy 70\% (95\% CI: 53.5-83.4\%).

When the cases were defined as the 5 participants who met the full DSM-IV ADHD criteria, including the age of onset and functional impairment criteria, the ASRS-v1.1 produced a substantially lower PPV and higher NPV, with similar total classification accuracy: sensitivity $60 \%$ (95\% CI: 14.7-94.7\%), specificity: $68.6 \%$ (95\% CI: 50.7-83.2\%), PPV 21.4\% (95\% CI: 10.3-39.4\%), NPV 92.3\% (95\% CI: $80.0-97.3 \%$ ) and total classification accuracy $67.5 \%$ (95\% CI: 50.9-81.4\%). All three full-syndrome combined type ADHD cases met the ASRS Part A threshold of $\geq 4$. The two full-syndrome ADHD cases who did not meet the ASRS Part A threshold were both inattentive type and both scored 3 on Part A.

We also examined the differences in frequency of endorsing ASRS-v1.1 items positively between the patients who were false positives on Part A of the ASRS-v1.1 $(n=11)$ versus those who met full-syndrome criteria for ADHD $(n=5)$ (Table 4). Items 5 and 6 from Part A, along with items 10, 11, 13 and 17 from Part B, all of which identify hyperactivity and impulsivity symptoms, showed greater specificity for full syndrome ADHD. 
2a. All patients

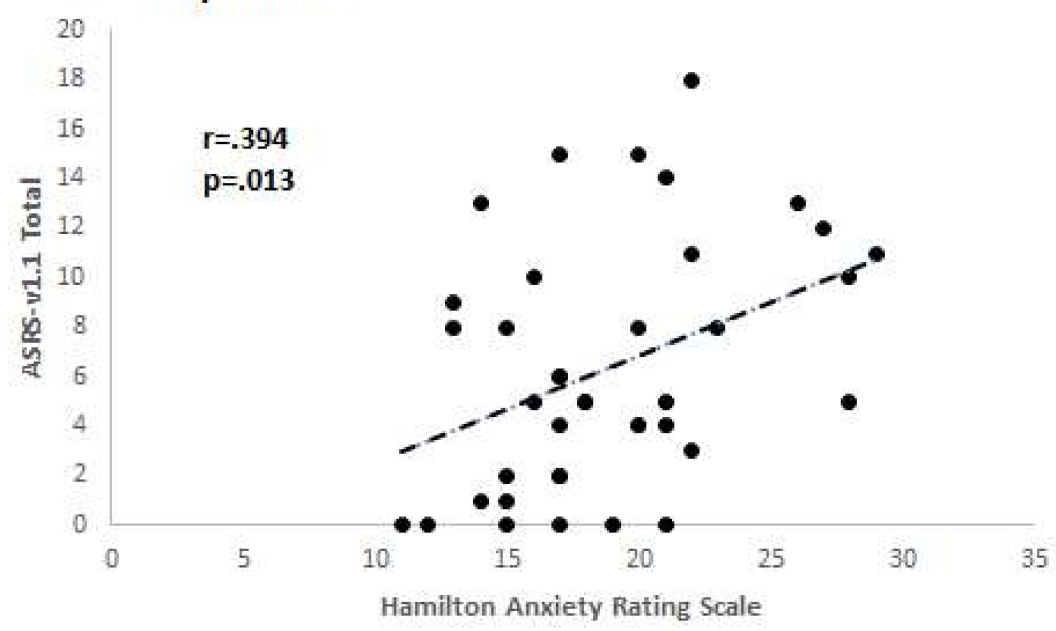

2b. ASRS v1.1 Screen negative

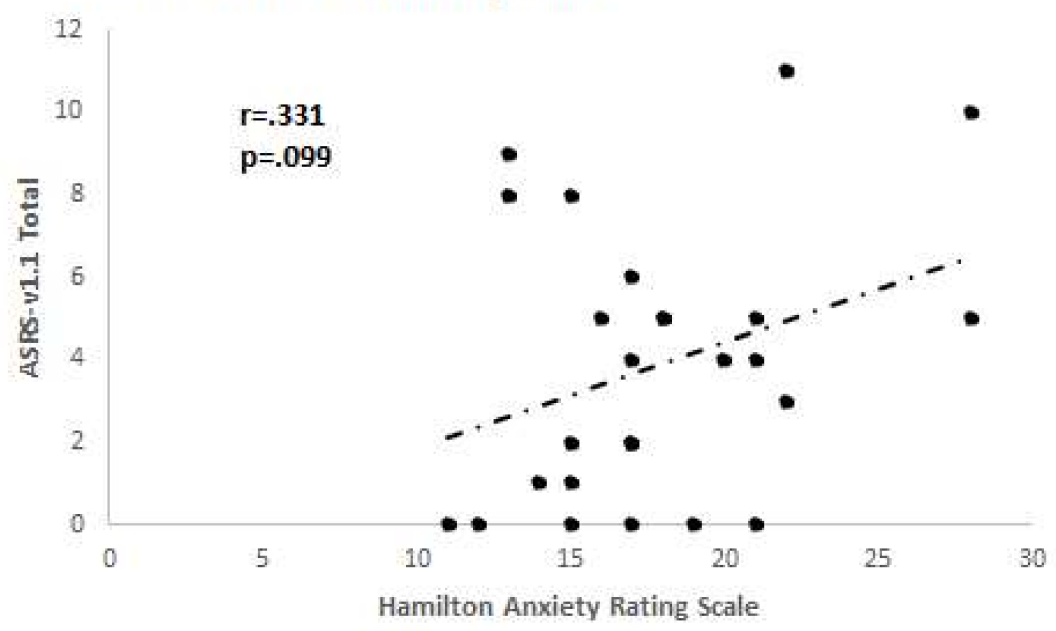

2c. ASRS v1.1 Screen positive

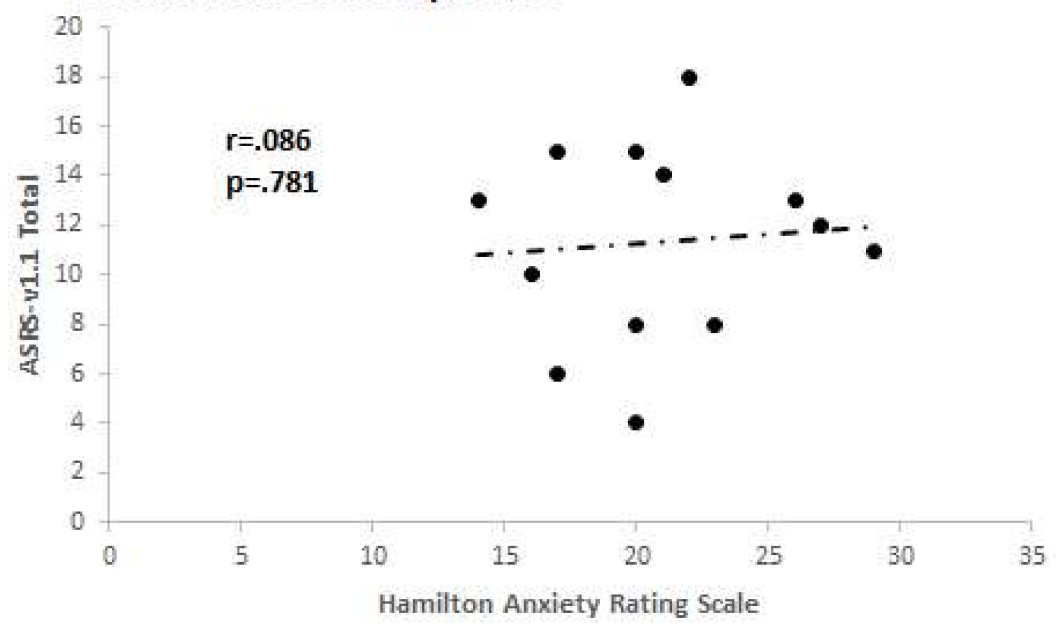

Figure 2. Correlations between anxiety and number of ASRS-v1.1 symptoms endorsed in depressed patients. (a) All depressed patients; (b) ASRS-v1.1 screen negative patients; (c) ASRS-v1.1 screen positive patients. 
Table 4. Frequency of positive endorsement of the six Part A ASRS-v1.1 items among MDD patients with a false positive ASRS-v1.1 Part A screen versus those with comorbid full syndrome ADHD.

\begin{tabular}{clcc}
\hline Item No. & \multicolumn{1}{c}{ Item Description } & $\begin{array}{c}\text { False Positive ASRS-v1.1 } \\
\text { Part A }(\boldsymbol{n}=\mathbf{1 1})\end{array}$ & $\begin{array}{c}\text { Full Syndrome } \\
\text { ADHD }(\boldsymbol{n}=\mathbf{5})\end{array}$ \\
\hline 1 & $\begin{array}{l}\text { Trouble wrapping up final details of } \\
\text { a project }\end{array}$ & $100 \%$ & $100 \%$ \\
\hline 2 & $\begin{array}{l}\text { Difficulty getting things in order for a } \\
\text { task requiring organization }\end{array}$ & $100 \%$ & $80 \%$ \\
\hline 3 & $\begin{array}{l}\text { Problems remembering appointments } \\
\text { or obligations }\end{array}$ & $100 \%$ & $60 \%$ \\
\hline 4 & $\begin{array}{l}\text { Avoiding getting started on a task } \\
\text { requiring a lot of thought }\end{array}$ & $27 \%$ \\
\hline 5 & $\begin{array}{l}\text { Fidget or squirm with your hands or } \\
\text { feet when you have to sit down for a } \\
\text { long time }\end{array}$ & $18 \%$ & $60 \%$ \\
\hline 6 & $\begin{array}{l}\text { Feel overly active and compelled to do } \\
\text { things, like you were driven by a motor }\end{array}$ & $20 \%$ \\
\hline
\end{tabular}

\section{Discussion}

To our knowledge, this is the first study to report on the performance of the ASRS-v1.1 as a screening instrument for ADHD in adults with a primary MDD diagnosis. The prevalence of full criteria DSM-IV ADHD was $12.5 \%$ among the depressed sample, which is similar to prior estimates in community (9.4\%) [4] and clinical MDD samples (8-14\%) [9,13]. In identifying full criteria ADHD, the ASRS demonstrated fair sensitivity (60\%) and specificity (68.6\%), a low PPV $(21.4 \%)$ and excellent NPV (92.3\%), with total classification accuracy of $67.5 \%$. When the definition of ADHD was broadened to include those patients who met only the symptom count criterion for inattentive, hyperactive-impulsive, or combined type (but not the DSM-IV age of onset or impairment criteria), sensitivity was similar but the specificity (85\%), PPV (78.6\%) were improved, though the NPV was reduced $(65.4 \%)$, resulting in similar total classification accuracy $(70 \%)$.

The high NPV of the ASRS-v1.1 is consistent with other studies examining the performance of the ASRS-v1.1 in patients with primary substance use disorders [18] and primary care settings [30,31]. Thus, the ASRS-v1.1 may have utility as a quick means for ruling out comorbid ADHD, because patients who test negative are unlikely to have the condition. However, it should be noted that two of the five true ADHD cases did not screen positive on the ASRS-v1.1, indicating that further evaluation for ADHD may be warranted if clinical suspicion is sufficiently high. A positive screen on the ASRS-v1.1 should always lead to careful subsequent evaluation by the clinician, as the positive predictive value is substantially lower (roughly 20-50\%) [18,30]. Thus, a positive Part A screening score on the ASRS-v1.1 is more likely to be a false positive than a true positive in patients with mood or substance disorders. It is also notable that $50 \%$ of the MDD sample endorsed sufficient numbers of symptoms on the MINI interview to meet the symptom count criteria for ADHD, which was a higher positive rate than the $35 \%$ who screened positive using the ASRS-v1.1 Part A. Consequently, neither simple symptom counts nor ASRS-v1.1 screening can be considered sufficient in themselves for determining ADHD diagnosis and treatment. This conclusion is supported by a recently study of 239 individuals repeatedly assessed for ADHD and other psychiatric and substance used disorders from childhood through young adulthood [32]. Roughly $95 \%$ of the subjects in this study who screened positive for ADHD using symptom checklists were ultimately found not to have late-onset ADHD, largely as a result of applying Criterion E (i.e., symptoms or impairment occurred as part of a comorbid psychiatric disorder or heavy substance use) [32].

The high potential for false positives using Part A of the ASRS-v1.1 to screen for ADHD is demonstrated in that of the five most frequently endorsed 18 ASRS-v1.1 items, four were from the six 
Part A items and all of them were inattention items (items 1-4). The other two Part A items that refer to hyperactivity, including "feeling driven by a motor", which was the least frequently endorsed of the 18 items.

Depressed patients screening positive on the ASRS-v1.1 reported significantly more anxiety and rumination than patients screening negative. Interestingly, neither anxiety nor rumination was associated with the ADHD symptoms as assessed by the structured MINI interview. Having any lifetime anxiety disorder was not associated with either ASRS-v1.1 or MINI ADHD symptom endorsement. These data suggest that anxious (compared to non-anxious) depression, defined as high levels of current anxiety symptoms is associated with greater subjective reports of inattention. One prior study found that anxious arousal but not anxious apprehension, was associated with greater cognitive impairments [33], which could explain this association. Whether anxious depression is more common among patients with comorbid ADHD has not previously been examined and warrants further study. We are unaware of any prior studies examining levels of rumination among patients with ADHD; given that patients with ADHD frequently experience mind-wandering, which may be conceptualized as the opposite of rumination, this result was unexpected [34].

Impairments in cognitive control, specifically impaired inhibition, contribute to both ruminative thinking and reduced emotion regulation [35,36] and provide a potential mechanism to link the observed association between subjective levels of rumination and inattention in our sample. The cognitive load incurred by rumination likely reduces processing resources available for application to external material $[37,38]$, which manifests as impaired concentration or inattention. Another possibility is that highly ruminative patients, as a form of cognitive distortion, more extensively recall and emphasize their errors or limitations in cognition, resulting in high endorsement on self-reported measures of both rumination and inattention.

A recent important development in ADHD has been the emergence of epidemiologic evidence suggesting the existence of an adult-onset form of ADHD. Three large studies from New Zealand [7], the United Kingdom [39] and Brazil [40] reported rates of adult-onset ADHD of 2.7\%, 5.5\% and 10.3\%, respectively. In each study, the prevalence of adult-onset ADHD was greater than the prevalence of childhood-onset ADHD, which has led to concerns that the studies, all of which relied solely on self-report data to diagnose adult-onset ADHD, may have biased estimates [41]. It is also possible that many of the identified adult-onset cases represented the delayed full expression of sub-syndromal cases of childhood ADHD [42]. Such patients would not qualify for ADHD as defined by the DSM but nevertheless may share a vulnerability to the disorder that becomes manifest through the accumulation of stressors and possibly reduced parental support, during young adult years. That the prevalence of adult-onset ADHD is not as high as the epidemiologic studies suggest is supported by data from a specialty ADHD evaluation clinic in France, which identified adult-onset ADHD in only $7 \%$ of 446 patients specifically referred for ADHD evaluation [42]. Furthermore, only $2.8 \%$ of this sample had isolated adult-onset ADHD without a comorbid disorder, further highlighting the importance of mood and anxiety disorders as contributors to self-reported ADHD symptoms [43]. However, in this study the timing of onset of ADHD symptoms was assessed using retrospective clinical interviews, which may have introduced a recall bias into the assessments; the aforementioned epidemiologic studies all incorporated prospective follow-up data from childhood, minimizing the effect of this bias.

Limitations to this analysis include the relatively small sample size of depressed patients. However, the $12.5 \%$ prevalence of full syndrome ADHD in our MDD sample is consistent with other prevalence data in MDD patients [4,9,13]. This result, along with the racial diversity of the participants, suggest that the ADHD characteristics of our sample can be considered to be reasonably representative of adults with MDD. Another limitation was that we did not have informant reports, such as teacher's evaluations or parental input, which could have improved the veracity of our assessment of childhood ADHD symptoms [44]. Hence, it is possible that our results underestimated the true rate of ADHD in the sample and consequently underestimated the accuracy of the ASRS-v1.1 in MDD patients. 
Recently, the World Health Organization published a new scale for detecting ADHD in adults applying the DSM-5 criteria, the Adult ADHD Self-Report Scale (ASRS) [45]. This scale was found to have excellent operating characteristics, with a sensitivity and specificity exceeding $90 \%$ and a PPV of $67-83 \%$, depending on the sample. The improved performance may stem in part from the more relaxed criteria for diagnosing ADHD in adults using DSM-5, which has resulted in a near doubling of the prevalence of adult ADHD in the U.S. (from $4.4 \%$ with DSM-IV to $8.2 \%$ with DSM-5 criteria), thereby enhancing the PPV [40]. In considering these very strong measures of accuracy, it should be noted that DSM- 5 criterion E (specifying that symptoms are not better accounted for by another mental disorder) was only "indirectly" evaluated in these assessments of the screening instrument, without application of formal structured assessments [45] (p. 522). Given the results in the current analysis of treatment-seeking MDD patients, the DSM-5 ASRS may face the same challenges as the ASRS-v1.1, specifically the high rate of false positives among patients with mood disorders.

\section{Conclusions}

In adult MDD patients, detecting comorbid ADHD is challenging due to the overlap in cognitive symptoms between the disorders. Applying the ASRS-v1.1 as a screener in these patients can help rule out the presence of ADHD when the screening result is negative. However, positive ASRS-v1.1 screen results are more likely to be false positives rather than true positives. Consequently, treatment for ADHD among MDD patients who screen positive on the ASRS-v1.1 should only be initiated after careful clinician evaluation of the time course of the ADHD symptoms and their relationship to major depressive episodes.

Author Contributions: B.W.D. developed the study and supervised the analysis. R.W. conducted the statistical analysis and K.H. conducted study assessments. B.W.D., R.W. and K.H. wrote the manuscript.

Conflicts of Interest: The authors declare no conflict of interest. Dunlop reports research funds from Acadia, Axsome, Janssen, National Institute of Mental Health and Takeda.

\section{References}

1. American Psychiatric Association. Diagnostic and Statistical Manual of Mental Disorders, 5th ed.; American Psychiatric Publishing: Arlington, VA, USA, 2013.

2. Hechtman, L.; Swanson, J.M.; Sibley, M.H.; Stehli, A.; Owens, E.B.; Mitchell, J.T.; Arnold, L.E.; Molina, B.S.; Hinshaw, S.P.; Jensen, P.S.; et al. MTA Cooperative Group. Functional adult outcomes 16 Years after childhood diagnosis of attention-deficit/hyperactivity disorder: MTA results. J. Am. Acad. Child. Adolesc. Psychiatry 2016, 55, 945-952. [CrossRef] [PubMed]

3. Fayyad, J.; De Graaf, R.; Kessler, R.; Alonso, J.; Angermeyer, M.; Demyttenaere, K.; De Girolamo, G.; Haro, J.M.; Karam, E.G.; Lara, C.; et al. Cross-national prevalence and correlates of adult attention-deficit hyperactivity disorder. Br. J. Psychiatry 2007, 190, 402-409. [CrossRef] [PubMed]

4. Kessler, R.C.; Adler, L.; Barkley, R.; Biederman, J.; Conners, C.K.; Demler, O.; Faraone, S.V.; Greenhill, L.L.; Howes, M.J.; Secnik, K.; et al. The prevalence and correlates of adult AHD in the United States: Results from the National Comorbidity Survey Replication. Am. J. Psychiatry 2006, 163, 716-723. [CrossRef] [PubMed]

5. Matza, L.S.; Paramore, C.; Prasad, M. A review of the economic burden of ADHD. Cost Eff. Resour. Alloc. 2005, 3, 5. [CrossRef] [PubMed]

6. Fletcher, J.; Wolfe, B. Long-term consequences of childhood ADHD on criminal activities. J. Ment. Health Policy Econ. 2009, 12, 119-138. [CrossRef] [PubMed]

7. Moffitt, T.E.; Houts, R.; Asherson, P.; Belsky, D.W.; Corcoran, D.L.; Hammerle, M.; Harrington, H.; Hogan, S.; Meier, M.H.; Polanczyk, G.V.; et al. Is adult ADHD a childhood-onset neurodevelopmental disorder? evidence from a four-decade longitudinal cohort study. Am. J. Psychiatry 2015, 172, 967-977. [CrossRef] [PubMed]

8. Kessler, R.C.; Chiu, W.T.; Demler, O.; Walters, E.E. Prevalence, severity, and comorbidity of 12-month DSM-IV disorders in the National Comorbidity Survey Replication. Arch. Gen. Psychiatry 2005, 62, 617-627. [CrossRef] [PubMed] 
9. Gao, K.; Wang, Z.; Chen, J.; Kemp, D.E.; Chan, P.K.; Conroy, C.M.; Serrano, M.B.; Ganocy, S.J.; Calabrese, J.R. Should an assessment of Axis I comorbidity be included in the initial diagnostic assessment of mood disorders? Role of QIDS-16-SR total score in predicting number of Axis I comorbidity. J. Affect. Disord. 2013, 148, 256-264. [CrossRef] [PubMed]

10. Biederman, J. Impact of comorbidity in adults with attention-deficit/hyperactivity disorder. J. Clin. Psychiatry 2004, 65 (Suppl. 3), 3-7. [PubMed]

11. Biederman, J.; Petty, C.R.; Fried, R.; Kaiser, R.; Dolan, C.R.; Schoenfeld, S.; Doyle, A.E.; Seidman, L.J.; Faraone, S.V. Educational and occupational underattainment in adults with attention-deficit/hyperactivity disorder: A controlled study. J. Clin. Psychiatry 2008, 69, 1217-1222. [CrossRef] [PubMed]

12. Ljung, T.; Chen, Q.; Lichtenstein, P.; Larsson, H. Common etiological factors of attention-deficit/hyperactivity disorder and suicidal behavior: A population-based study in Sweden. JAMA Psychiatry 2014, 71, 958-964. [CrossRef] [PubMed]

13. Alpert, J.E.; Maddocks, A.; Nierenberg, A.A.; O'Sullivan, R.; Pava, J.A.; Worthington, J.J., III; Biederman, J.; Rosenbaum, J.F.; Fava, M. Attention deficit hyperactivity disorder in childhood among adults with major depression. Psychiatry Res. 1996, 62, 213-219. [CrossRef]

14. Diler, R.S.; Daviss, W.B.; Lopez, A.; Axelson, D.; Iyengar, S.; Birmaher, B. Differentiating major depressive disorder in youths with attention deficit hyperactivity disorder. J. Affect. Disord. 2007, 102, 125-130. [CrossRef] [PubMed]

15. Murphy, K.R.; Adler, L.A. Assessing attention-deficit/hyperactivity disorder in adults: Focus on rating scales. J. Clin. Psychiatry 2004, 65 (Suppl. 3), 12-17. [PubMed]

16. Surman, C.B.H. Clinical assessment of ADHD in adults. In ADHD in Adults: A Practical Guide to Evaluation and Management; Humana Press: New York, NY, USA, 2013.

17. Kessler, R.C.; Adler, L.; Ames, M.; Demler, O.; Faraone, S.; Hiripi, E.; Howes, M.J.; Jin, R.; Secnik, K.; Spencer, T; et al. The World Health Organization Adult ADHD Self-Report Scale (ASRS): A short screening scale for use in the general population. Psychol. Med. 2005, 35, 245-256. [CrossRef] [PubMed]

18. Reyes, M.M.; Schneekloth, T.D.; Hitschfeld, M.J.; Geske, J.R.; Atkinson, D.L.; Karpyak, V.M. The clinical utility of ASRS-v1.1 for identifying ADHD in alcoholics using PRISM as the reference standard. J. Atten. Disord. 2016. [CrossRef] [PubMed]

19. Perroud, N.; Cordera, P.; Zimmermann, J.; Michalopoulos, G.; Bancila, V.; Prada, P.; Dayer, A.; Aubry, J.M. Comorbidity between attention deficit hyperactivity disorder (ADHD) and bipolar disorder in a specialized mood disorders outpatient clinic. J. Affect. Disord. 2014, 168, 161-166. [CrossRef] [PubMed]

20. Dalsgaard, S.; Kvist, A.P.; Leckman, J.F.; Nielsen, H.S.; Simonsen, M. Cardiovascular safety of stimulants in children with attention-deficit/hyperactivity disorder: A nationwide prospective cohort study. J. Child Adolesc. Psychopharmacol. 2014, 24, 302-310. [CrossRef] [PubMed]

21. Alexander, L.; Oliver, A.; Burdine, L.K.; Tang, Y.; Dunlop, B.W. Reported maladaptive decision-making styles in unipolar and bipolar depression and their change with treatment. Psychiatry Res. 2017, 257, 386-392. [CrossRef] [PubMed]

22. Hamilton, M. A rating scale for depression. J. Neurol. Neurosurg. Psychiatry 1960, 23, 56-62. [CrossRef] [PubMed]

23. First, M.B.; Spitzer, R.L.; Gibbon, M.; Williams, J.B.W. Structured Clinical Interview for DSM-IV Axis I Disorders-Patient Edition (SCID-I/P, Version 2.0); Biometrics Research Department, New York State Psychiatric Institute: New York, NY, USA, 1995.

24. Sheehan, D.V.; Lecrubier, Y.; Sheehan, K.H.; Amorim, P.; Janavs, J.; Weiller, E.; Hergueta, T.; Baker, R.; Dunbar, G.C. The Mini-International Neuropsychiatric Interview (M.I.N.I.): The development and validation of a structured diagnostic psychiatric interview for DSM-IV and ICD-10. J. Clin. Psychiatry 1998, 59 (Suppl. 20), 22-33. [PubMed]

25. Guy, W. Clinical Global Impressions. Publication ADM 76-338. ECDEU Assessment Manual for Psychopharmacology; US Department of Health, Education, and Welfare: Rockville, MD, USA, 1976; pp. 217-222.

26. Hamilton, M. The assessment of anxiety states by rating. Br. J. Med. Psychol. 1959, 32, 50-55. [CrossRef] [PubMed]

27. Treynor, W.; Gonzalez, R.; Nolen-Hoeksema, S. Rumination reconsidered: A psychometric analysis. Cog. Ther. Res. 2003, 27, 247-259. [CrossRef] 
28. Bernstein, D.P.; Fink, L. Childhood Trauma Questionnaire Manual; Psychological Corporation: San Antonio, TX, USA, 1998.

29. American Psychiatric Association. Diagnostic and Statistical Manual of Mental Disorders: DSM-IV-TR; American Psychiatric Association: Washington, DC, USA, 2000.

30. Kessler, R.C.; Adler, L.; Gruber, M.J.; Sarawate, C.A.; Spencer, T.; Van Brunt, D.L. Validity of the World Health Organization Adult ADHD Self-Report Scale (ASRS) Screener in a representative sample of health plan members. Int. J. Met. Psychiatr. Res. 2007, 16, 52-65. [CrossRef] [PubMed]

31. Hines, J.L.; King, T.S.; Curry, W.J. The adult ADHD self-report scale for screening for adult attention deficit-hyperactivity disorder (ADHD). J. Am. Board Fam. Med. 2012, 25, 847-853. [CrossRef] [PubMed]

32. Sibley, M.H.; Rohde, L.A.; Swanson, J.M.; Hechtman, L.T.; Molina, B.S.G.; Mitchell, J.T.; Arnold, L.E.; Caye, A.; Kennedy, T.M.; Roy, A.; et al. Late-Onset ADHD reconsidered with comprehensive repeated assessments between ages 10 and 25. Am. J. Psychiatry 2018, 175, 140-149. [CrossRef] [PubMed]

33. Quinn, C.R.; Harris, A.; Felmingham, K.; Boyce, P.; Kemp, A. The impact of depression heterogeneity on cognitive control in major depressive disorder. Aust. N. Z. J. Psychiatry 2012, 46, 1079-1088. [CrossRef] [PubMed]

34. Christoff, K.; Irving, Z.C.; Fox, K.C.; Spreng, R.N.; Andrews-Hanna, J.R. Mind-wandering as spontaneous thought: A dynamic framework. Nat. Rev. Neurosci. 2016, 17, 718-731. [CrossRef] [PubMed]

35. Joormann, J.; Gotlib, I.H. Emotion regulation in depression: Relation to cognitive inhibition. Cogn. Emot. 2010, 24, 281-298. [CrossRef] [PubMed]

36. Whitmer, A.J.; Gotlib, I.H. An attentional scope model of rumination. Psychol. Bull. 2013, 139, $1036-1061$. [CrossRef] [PubMed]

37. Watkins, E.; Brown, R.G. Rumination and executive function in depression: An experimental study. J. Neurol. Neurosurg. Psychiatry 2002, 72, 400-402. [CrossRef] [PubMed]

38. Jones, N.P.; Siegle, G.J.; Muelly, E.R.; Haggerty, A.; Ghinassi, F. Poor performance on cognitive tasks in depression: Doing too much or not enough? Cogn. Affect. Behav. Neurosci. 2010, 10, 129-140. [CrossRef] [PubMed]

39. Agnew-Blais, J.C.; Polanczyk, G.V.; Danese, A.; Wertz, J.; Moffitt, T.E.; Arseneault, L. Evaluation of the persistence, remission, and emergence of attention-deficit/hyperactivity disorder in young adulthood. JAMA Psychiatry 2016, 73, 713-720. [CrossRef] [PubMed]

40. Caye, A.; Rocha, T.B.-M.; Anselmi, L.; Murray, J.; Menezes, A.M.; Barros, F.C.; Gonçalves, H.; Wehrmeister, F.; Jensen, C.M.; Steinhausen, H.C.; et al. Attention-deficit/hyperactivity disorder trajectories from childhood to young adulthood: Evidence from a birth cohort supporting a late-onset syndrome. JAMA Psychiatry 2016, 73, 705-712. [CrossRef] [PubMed]

41. Faraone, S.V.; Biederman, J. Can attention-deficit/hyperactivity disorder onset occur in adulthood? JAMA Psychiatry 2016, 73, 655-656. [CrossRef] [PubMed]

42. Lecendreux, M.; Konofal, E.; Cortese, S.; Faraone, S.V. A 4-year follow-up of attention-deficit/hyperactivity disorder in a population sample. J. Clin. Psychiatry 2015, 76, 712-719. [CrossRef] [PubMed]

43. Lopez, R.; Micoulaud-Franchi, J.A.; Galera, C.; Dauvilliers, Y. Is adult-onset attention deficit/hyperactivity disorder frequent in clinical practice? Psychiatry Res. 2017, 257, 238-241. [CrossRef] [PubMed]

44. Sibley, M.H.; Mitchell, J.T.; Becker, S.P. Method of adult diagnosis influences estimated persistence of childhood ADHD: A systematic review of longitudinal studies. Lancet Psychiatry 2016, 3, 1157-1165. [CrossRef]

45. Ustun, B.; Adler, L.A.; Rudin, C.; Faraone, S.V.; Spencer, T.J.; Berglund, P.; Gruber, M.J.; Kessler, R.C. The World Health Organization Adult Attention-Deficit/Hyperactivity Disorder Self-Report Screening Scale for DSM-5. JAMA Psychiatry 2017, 74, 520-526. [CrossRef] [PubMed]

(C) 2018 by the authors. Licensee MDPI, Basel, Switzerland. This article is an open access article distributed under the terms and conditions of the Creative Commons Attribution (CC BY) license (http://creativecommons.org/licenses/by/4.0/). 